\title{
Historias cruzadas X Gekreuzte Geschichten. Ein interdisziplinäres Gedenkprojekt über den März 1938, Diktatur, Exil und Migration im globalhistorischen Licht österreichisch- mexikanischer Beziehungen
}

Berthold Molden

\section{CpenEdition}

\section{Journals}

Édition électronique

URL : http://journals.openedition.org/austriaca/658

DOI : 10.4000/austriaca.658

ISSN : 2729-0603

Éditeur

Presses universitaires de Rouen et du Havre

Édition imprimée

Date de publication : 1 juin 2018

Pagination : $247-249$

ISBN : 979-10-240-1233-9

ISSN : 0396-4590

\section{Référence électronique}

Berthold Molden, „Historias cruzadas X Gekreuzte Geschichten. Ein interdisziplinäres Gedenkprojekt über den März 1938, Diktatur, Exil und Migration im globalhistorischen Licht österreichischmexikanischer Beziehungen", Austriaca [Online], 86 | 2018, Online erschienen am: 01 Juli 2020, abgerufen am 28 Januar 2021. URL: http://journals.openedition.org/austriaca/658 ; DOI: https:// doi.org/10.4000/austriaca.658 
umfangreichen Sammlungen hingegen werden die Erinnerung an ihn und eine kritische österreichische Zeitgeschichte wach halten.

Oliver RATHKOLB

\section{Historias cruzadas X Gekreuzte Geschichten.}

Ein interdisziplinäres Gedenkprojekt über den

März 1938, Diktatur, Exil und Migration im globalhistorischen Licht österreichisch-mexikanischer Beziehungen

In das multiple österreichische Gedenkjahr 2018 fand auch die Globalgeschichte Eingang. Der Historiker Berthold Molden konzipierte gemeinsam mit KünstlerInnen und KulturwissenschaftlerInnen eine interdisziplinäre und transnationale Veranstaltungsreihe. Zentrum ist ein globaler Erinnerungsort: der Mexikopatz in Wien.

Der Mexikoplatz verdankt seinen Namen der Erinnerung an den Protest gegen die Annexion Österreichs durch das Deutsche Reich, den Mexiko im März 1938 als einziges Land vor dem Völkerbund erhob. Dieser Moment war nicht nur für die österreichische Geschichte bedeutsam, sondern auch für die Globalgeschichte des 20. Jahrhunderts. Das kleine Österreich verschwand von der Landkarte. Und das ferne, eben aus einer langen Revolution hervorgegangene Mexiko legte dagegen einsamen Protest ein, während es sich selbst gegenüber dem mächtigen Nachbarn USA zu behaupten versuchte - ein historischer Berührungspunkt, der in vielerlei Hinsicht auf die globalen Entwicklungslinien dieses „Zeitalters der Extreme" verweist.

Doch neben diesem Schlüsseldatum, in das Diktatur und Exil eingeschrieben sind, haben auch andere Dimensionen des 20. Jahrhunderts auf dem Mexikoplatz Spuren hinterlassen: das Rote Wien der $20 e r$ und 3oer Jahre, die Remigration nach 1945, die Ankunft von GastarbeiterInnen in den 6oer und 7oer Jahren, die Immigration sowjetischer Jüdinnen und Juden in den 8oer Jahren und zuletzt Geflüchtete aus Afrika und dem Nahen Osten. Da all diese Gedächtnis-Schnittstellen transnationale Bezüge haben, machen sie den Mexikoplatz zu einem globalen Ort. Das Projekt „Gekreuzte Geschichten“ schafft durch die Aktualisierung von Geschichte mit künstlerischen Mitteln neue Identitätsangebote und 
bringt durch ein Vermittlungsprogramm verschiedene Segmente der Wiener Öffentlichkeit miteinander in Kommunikation.

"Gekreuzte Geschichten“ platziert den „Anschluss“ in einem historischen Entwicklungsbogen, der vom Anfang des 20. Jahrhunderts bis in unsere Gegenwart reicht. Ausgehend von dem mexikanischen Protest gegen die Nazi-Annexion Österreichs erzählt es eine vielfach verknüpfte Geschichte gesellschaftlicher und kultureller Kämpfe, von Verfolgung, Widerstand, Flucht und Exil in Österreich und Mexiko. Der symbolische "Gedächtnisort Anschluss 1938“ und der physische "Gedächtnisort Mexikoplatz" werden so gleichzeitig in einen globalen historischen Kontext gestellt und in aktuelle gesellschaftliche Debatten unserer Gegenwart eingeschrieben.

Gemeinsam mit HistorikerInnen setzen sich KünstlerInnen mit dem Gedenken an Diktatur und deren Überwindung, an Flucht, Migration und Neuanfang auseinander und stellen es in Bezug zu aktuellen Asyldebatten. Die Veranstaltungsreihe besteht aus unterschiedlichen Formaten: Der Grafikkünstler Thomas Fatzinek schuf eine Serie von 20 Linoldrucken, die gemeinsam mit Texten von Berthold Molden auf vier Littfasssäulen im Zentrum des Mexikoplatzes zu sehen sind. Mit stilistischer Bezugnahme auf die mexikanische Revolutionsgrafik brachte Fatzinek die komplexen historischen Zusammenhänge in eine zugängliche erzählerische Form. Von März bis Oktober 2018 stellt diese Schau den Hauptanker des Projektes im öffentlichen Raum und auf der Webseite www.mexikoplatz.org dar. Andere temporäre Interventionen vertieften die gegenwartsrelevanten Aspekte des Projektes. Unter Leitung der Filmwissenschaftlerin Doris Posch initierte das Filmprojekt „Der exilierte Blick“ fünf Kurzfilme von FilmemacherInnen mit Migrationshintergrund, die sich mit Flucht nach Österreich und der historischen Aufladung Österreichs befassen. In diesem Zusammenhang erarbeiteten die mexikanischen KünstlerInnen Mariél Rodríguez und Rodrigo Martínez eine Ausstellung in Wien, die die Heldenerzählung vom antifaschistischen Fluchtland Mexiko kritisch hinterfragte. Und im September eröffnete, kuratiert von Nina Höchtl und Julio García Murillo, die Ausstellung „Das Recht der Anderen“ zuerst in Wien und dann in Mexiko; auch in diesem Rahmen wurden historische Berührungspunkte zwischen Österreich und Mexiko - von Maximilian bis ins 20. Jahrhundert - einer Revision unterzogen. Recherche wurde zur künstlerischen Strategie und Kunst zum Ausdruck historischer Forschung. Zusätzlich schloss sich die österreichische Botschaft in Mexiko 
mit einer Veranstaltungsreihe in Mexiko Stadt an das Projekt an und präsentierte dessen Kernthemen einem mexikanischen Publikum.

Ebenso vielfältig wie die Methoden des Projektes waren seine Zielgruppen: ein historisch und kulturell interessiertes Publikum, wissenschaftliches Fachpublikum sowie AnrainerInnen des Mexikoplatzes und Asylsuchende. Eine Reihe von Vermittlungsveranstaltungen - Podiumsdiskussionen mit ZeitzeugInnen und KünstlerInnen, Performances der Gruppe „Museum auf der Flucht“ sowie Konzerte - machten den Mexikoplatz acht Monate lang zu einem geschichtspolitischen Begegnungsort in Wien. Gerade für neu nach Österreich und Wien gekommene Menschen entstand die Möglichkeit, sich der österreichischen Geschichte über ihre eigene Erfahrung anzunähern. Gleichzeitig konnten „MehrheitswienerInnen" ungeahnte Parallelen zwischen der österreichischen Vergangenheit und der aktuellen Realität der Neo-ÖsterreicherInnen entdecken.

Berthold MoLDEN 